\title{
Information and News
}

\section{MEETINGS}

- $\quad 42^{\text {nd }}$ Anatomical Society of Southern Africa Conference: Stellenbosch, South Africa, April 13 to $16,2014$.

- 18th Congress of the International Federation of Associations of Anatomists (IFAA): Beijing, China, August 8 to 10, 2014. http://www.csas.org.cn.

- III Teaching and Research Meeting on Clinical Anatomy: Salta, Argentina, September 18 to 20 , 2014. (Find the $1^{\text {st }}$ announcement below). 

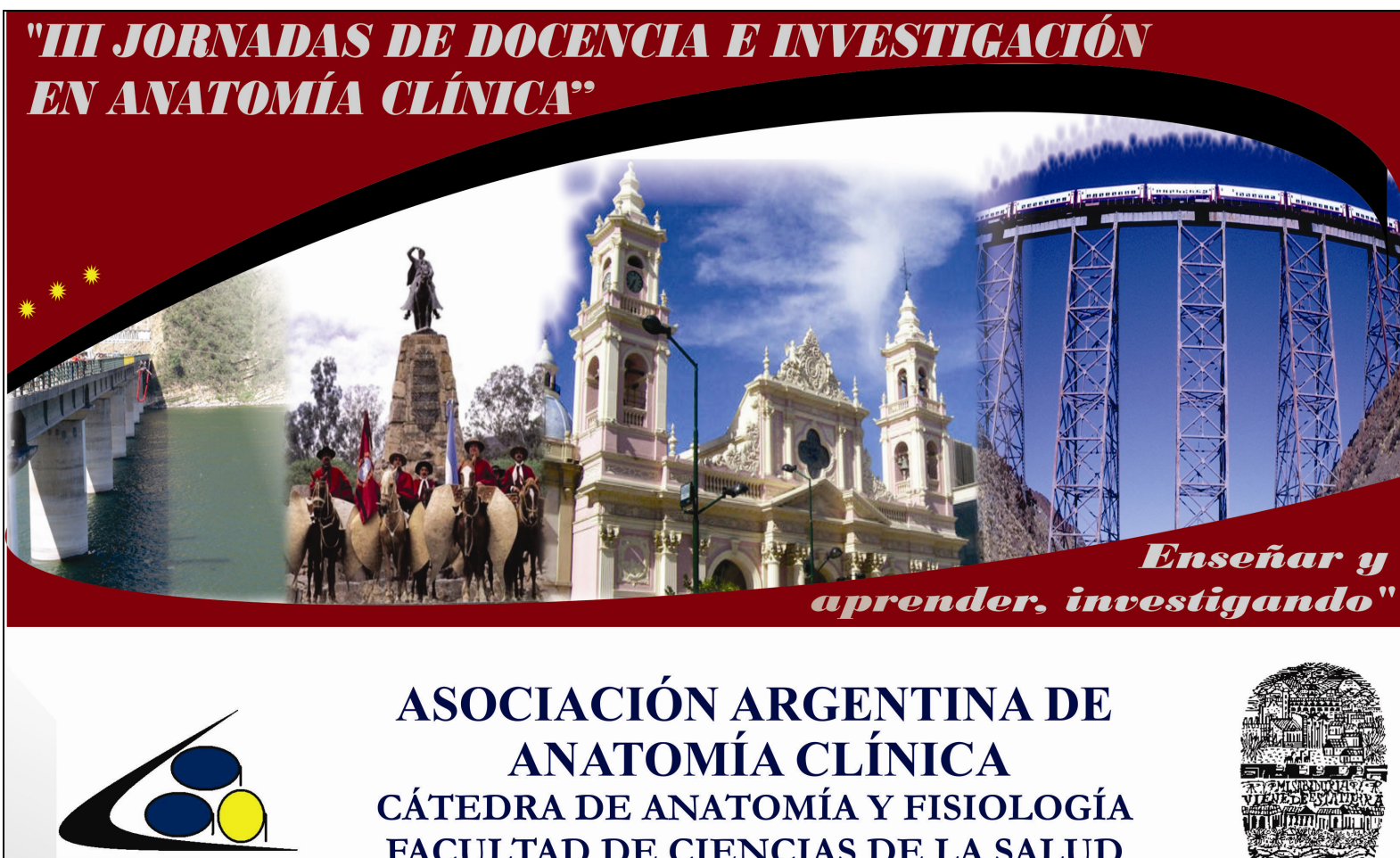

ASOCIACIÓN ARGENTINA DE ANATOMÍA CLÍNICA CÁTEDRA DE ANATOMÍA Y FISIOLOGÍA FACULTAD DE CIENCIAS DE LA SALUD UNIVERSIDAD NACIONAL DE SALTA

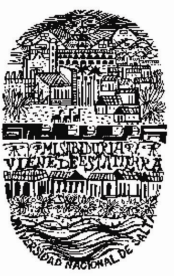

\section{DIRIGIDO A EQUIPOS DE SALUD}

SESIONES ESPECIALES

Médicos-Residentes- Enfermeros- Estudiantes

* Posters

* Desayuno con Expertos

Fecha: 18 al 20 de Septiembre de 2014

Lugar: Universidad Nacional de Salta

Avda. Bolivia 5150. Salta. Capital

Informes

Email: anatomiaunsa@hotmail.com

Web: www.aaaclinica.com.ar

Contactos: (0387) 156055747-(0387)154535065

(0387) 154084487-(0387)155218200-(0387) 4258639

\section{AUSPICIAN}
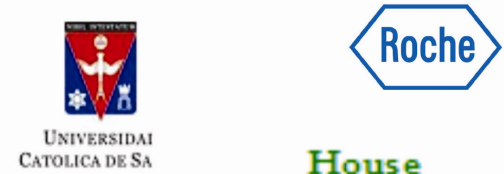

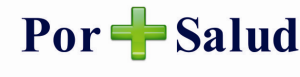
Cocabola

House

Medicina estético

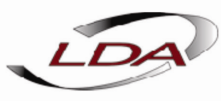

La Negrita Regionales 